\title{
Role of cytological characteristics of benign thyroid nodules on effectiveness of their treatment with levothyroxine
}

\author{
Mustafa Cesur', Mehtap Akcil², Sibel Ertek ${ }^{3}$, Rifat Emral ${ }^{4}$, Safak Bulut ${ }^{5}$, Sevim Gullu ${ }^{4}$, Demet Corapcioglu ${ }^{4}$
}

1Department of Endocrinology and Metabolic Diseases, Ankara Guven Hospital, Ankara, Turkey

2Department of Statistics and Computer Science, Baskent University Faculty of Science and Letters, Ankara, Turkey

${ }^{3}$ Department of Endocrinology and Metabolism, Medical Faculty, Ufuk University, Ankara, Turkey

${ }^{4}$ Department of Endocrinology and Metabolic Diseases, Ankara University School of Medicine, Ankara, Turkey

${ }^{5}$ Department of Pathology, Ankara University School of Medicine, Ankara, Turkey

Submitted: 11 March 2012

Accepted: 15 August 2012

Arch Med Sci 2013; 9, 6: 1083-1089

DOI: 10.5114/aoms.2013.39796

Copyright @ 2013 Termedia \& Banach

\begin{abstract}
Introduction: Levothyroxine (LT4) therapy has been used for the treatment of euthyroid nodular goiter, but there are controversial results about its usefulness. We aimed to evaluate the possible role of benign nodules' cytological characteristics in response to LT4 therapy.

Material and methods: In total, 93 patients with 128 nodules were included in the study; 74 of the nodules were treated with LT4 (group 1), and 54 of them had no medication (group 2). The subgroups consisted of adenomatous nodules, colloid nodules and cystic nodules.

Results: In group 1, mean thyroid volume and mean nodule volume were reduced significantly ( $p=0.002$ and $p=0.022$, respectively) with low-normal level thyrotropin (TSH) suppression (between $0.3 \mathrm{mIU} / \mathrm{ml}$ and $1.0 \mathrm{mIU} / \mathrm{ml}$ ), while there were no significant changes in group 2 . When we evaluated changes of the initial and last nodule volumes in cytological subgroups, only colloid nodules in group 1 had significant reduction $(p=0.040)$ and the others had no significant changes. By omitting the colloid nodules, when the other nodules were revaluated, there were no significant changes in either group.

Conclusions: On the basis of these results, obtained from a large sample of Anatolian patients, it is possible that LT4 therapy leads to significant reductions of both thyroid volume and nodule size in colloid nodules, but not in other kinds of benign nodules.
\end{abstract}

Key words: levothyroxine suppressive therapy, nodule treatment, colloid nodule, cystic nodule, adenomatous nodule, thyroid nodule, cytological features, levothyroxine.

\section{Introduction}

Levothyroxine (LT4) therapy has been used for the treatment of euthyroid diffuse and nodular goiters [1, 2], to suppress the secretion of thyrotropin (TSH) and reduce the nodule size. The assumption underlying this

\author{
Corresponding author: \\ Dr Sibel Ertek \\ Ufuk University \\ Medical Faculty \\ Department of Endocrinology \\ and Metabolism \\ Dr. Ridvan Ege Hospital \\ Mevlana Bulvari 86-88 \\ 06520 Ankara, Turkey \\ Phone: +905337156519 \\ E-mail: sibelertek@yahoo.it
}


treatment is that the growth of thyroid nodules, like that of normal thyroid tissue, is dependent on TSH that acts as a growth factor, and suppression of TSH secretion will remove this growth stimulus and cause decrease in size or stabilization $[3,4]$. But there are controversial reports about the effectiveness of thyroid hormone suppressive therapy in reducing the volume of benign thyroid nodules [58]. Some authors suggest that LT4 therapy is effective in reducing the thyroid nodules [9-12] as well as in preventing the further development of additional nodules [13-15], but some others conclude that LT4 therapy is not effective in reducing the nodule size and in general this attitude was abandoned, except for small colloid nodules in iodine deficient areas [16-19]. Recently this discussion started again with some small clinical studies suggesting that LT4 treatment decreases nodule size [19-21].

In some studies, benign nodules are treated with LT4 at suppressive doses. Koc et al. showed that low level and high level TSH suppression are equally effective in reducing nodule size [12]. In a study performed by Wemeau et al., $17 \%$ of the placebo treated nodules shrank in size by more than $50 \%$ during the observation period. The LT4 treated group had a similar size reduction in $27 \%$ of the patients [13]. Growth factors other than TSH may impact on the growth of thyroid cells and possibly on nodules [22]. In this context, it could be useful for the clinician to know the probability of a nodule undergoing a clinically relevant volume reduction after LT4 therapy. Small nodules were suggested to be more likely to shrink in response to LT4 therapy [5].

Fine needle aspiration biopsy (FNAB) has been widely accepted as an excellent diagnostic tool in evaluation of thyroid nodules [23]. Fine needle aspiration biopsy may help to differentiate the nodules as benign or malign according to the cytological findings. Cytological characteristics of the benign nodules were also suggested to play a role in response to the LT4 therapy [24].

But since recent studies generally do not consider type of nodule when evaluating response to TSH suppression [25], we aimed to evaluate whether benign thyroid nodules with different cytological characteristics could differently answer to LT4 therapy in the central Anatolian region following successful iodine supplementation [26-28].

\section{Material and methods}

Ninety-three patients (80 females and 13 males) with 128 thyroid nodules were included in the study consecutively. All patients were euthyroid at the beginning of the study. Subjects were randomly separated into two groups: 74 of the nodules (from 41 females and 7 males) were treated with LT4 and composed the treatment group (group 1); 54 of them (from 39 females and 6 males) had neither medication nor placebo and composed the nontreatment group (group 2).

All subjects were evaluated prospectively for 12 months by calling control visits every 3 months. We treated the patients according to TSH levels and tried to keep them in the range $0.3-1.0 \mathrm{mIU} / \mathrm{ml}$. Mean LT4 dose in the treatment group was 32.3 $\pm 11.2 \mu \mathrm{g} /$ day. Two different cytologists evaluated the specimens after FNAB independently and if they concluded on the same cytological result, the nodule was included in the study. Patients were excluded if they had a nodule with a mixed solid-cystic component, hyperplastic nodule, suspicious or nondiagnostic nodule, subclinical or overt hyperthyroidism and hypothyroidism, autoimmune thyroid disease, thyroid cancer, known cardiovascular disease or other significant co-morbid illness.

To evaluate the effect of cytological characteristics on nodule shrinkage, nodules were grouped according to their cytological features; three different cytological characteristics were determined according to previous reports [29-31] and included in the study:

1) adenomatous nodule (nodular goiter): degenerative changes had priority in the specimen; the number of nodules is 33 and 20 in group 1 and 2, respectively;

2) colloid nodule: the nodule had plenty of colloid; the number of nodules is 18 and 15 in group 1 and 2, respectively;

3) cystic nodule: the nodule had rich cystic contents on cytology and totally cystic appearance on ultrasonography without a solid component; the number of nodules is 23 and 19 in group 1 and 2, respectively.

The Institutional Ethical Committee approved the study, and informed consent was provided by all participants of the study.

Total volume of thyroid and the nodules, free T3 (FT3), free T4 (FT4), TSH, anti-thyroglobulin (Anti$\mathrm{Tg}$ ), and anti-thyroid peroxidase (Anti-TPO) were evaluated for all subjects. Ultrasonographic evaluation was made by real-time B-mode thyroid ultrasonography (General Electric ${ }^{\circledR}$, Logic 200) using a $7.5 \mathrm{mHz}$ transducer in the Ultrasonography Imaging and Intervention Laboratory of Endocrinology and Metabolic Diseases Department of Ankara University Medical School. Volumes were calculated using the formula [height $(a) \times$ length $(b) \times$ thickness $(c) \times$ $\pi / 6)$ ]. The volumes of both thyroid lobes were calculated separately and the sum of the volumes of both lobes was accepted as thyroid volume [32].

Free T3 and FT4 levels were measured by a chemiluminescent method using ACS:180 ${ }^{\circledR}$ (Bayer Corporation, New York-USA) kit (normal ranges: 2.8$7 \mathrm{pmol} / \mathrm{l}$ and 10-23 pmol/l, respectively). Thyrotropin was measured by a third generation 
Table I. Changes in TSH levels in treatment and non-treatment groups

\begin{tabular}{|lccc|}
\hline Cytological feature & Initial TSH & Last TSH & Value of $p$ \\
\hline Treatment group (group 1; $n=74)$, mean \pm SD & $1.28 \pm 0.85$ & $0.81 \pm 0.37$ & $<0.001$ \\
\hline Adenomatous nodules $(n=33)$ & $1.19 \pm 0.13$ & $0.80 \pm 0.07$ & 0.018 \\
\hline Colloid nodules $(n=18)$ & $1.47 \pm 0.86$ & $0.93 \pm 0.15$ & 0.010 \\
\hline Cystic nodules $(n=23)$ & $1.31 \pm 0.58$ & $0.74 \pm 0.27$ & 0.001 \\
\hline Non-treatment group (group 2; $n=54)$, mean \pm SD & $1.18 \pm 0.69$ & $1.09 \pm 0.61$ & 0.546 \\
\hline Adenomatous nodules $(n=20)$ & $1.11 \pm 0.56$ & $1.14 \pm 0.73$ & 0.876 \\
\hline Colloid nodules $(n=15)$ & $1.09 \pm 0.16$ & $1.07 \pm 0.32$ & 0.637 \\
\hline Cystic nodules $(n=19)$ & $1.21 \pm 0.63$ & $1.01 \pm 0.22$ & 0.191 \\
\hline
\end{tabular}

TSH - thyrotropin

immunometric chemiluminescent method using Immulite $2000^{\circledR}$ (DPC, Los Angeles-USA) kit (normal range: $0.35-5.5 \mathrm{mlU} / \mathrm{ml}$ ). Anti-Tg and Anti-TPO levels were measured by a competitive radioimmunoassay method using Brahms ${ }^{\circledR}$ (Dynotest) kits (normal ranges $0-40 \mathrm{U} / \mathrm{ml}$ for both).

\section{Statistical analysis}

Results are expressed as mean, standard deviation, median and range. Data were tested for normality by the one-sample Kolmogorov-Smirnov test and logarithmic transformation was used, if necessary. After making logarithmic transformation of data, parametric statistical tests were applied for comparison.

Changes in nodule volume size between initial and last evaluations were assessed by means of the paired sample $t$ test. In analysis of three different cytological groups, one-way analysis of variance was used. The $\chi^{2}$ analyses were applied to test proportional change of nodule volume size between initial and last evaluations. Values of $p$ less than 0.05 were accepted as statistically significant. Statistical analyses were carried out with Statistical Packages for Social Sciences (SPSS) (version 13.0; SPSS, Inc Chicago).

\section{Results}

Mean age of the subjects was $43.2 \pm 9.4$ years. No difference in age was observed among three cytological groups in both group 1 and 2 ( $p=0.98$, $p=0.95$, respectively). Mean TSH level decreased from $1.28 \pm 0.85 \mathrm{mlU} / \mathrm{ml}$ to $0.81 \pm 0.37 \mathrm{mIU} / \mathrm{ml}$ in group 1 at the end of the study and the change was statistically significant $(p<0.001)$ while there was no significant change in group 2 (Table I). Changes in ST3 and ST4 had no statistical significance in all groups.

We evaluated all patients for thyroid volume and nodule volume changes after the follow-up period. When whole subjects in both groups were considered, the mean thyroid volume had changed from
$25.54 \pm 13.05 \mathrm{ml}$ to $26.47 \pm 17.35 \mathrm{ml}$ at the end of the follow-up period but that was not significant ( $p=$ $0.623)$. In group 1 , the mean thyroid volume was $26.37 \pm 13.48 \mathrm{ml}$ and decreased to $23.05 \pm 10.99 \mathrm{ml}$; the difference was found statistically significant $(p=0.002)$. In group 2, it was $24.53 \pm 12.62 \mathrm{ml}$ and increased to $30.67 \pm 22.31 \mathrm{ml}$ and there was no statistically significant change $(p=0.121)$ (Figure 1$)$.

When whole subjects were taken into account, mean nodule volume changed from $2.36 \pm 2.68 \mathrm{ml}$ to $2.20 \pm 2.05 \mathrm{ml}(p=0.022)$. In group 1 , mean initial nodule volume was $2.57 \pm 2.97 \mathrm{ml}$ and decreased to $2.22 \pm 2.74 \mathrm{ml}$; the difference was found to be statistically significant $(p=0.009)$. In group 2 , mean nodule volume was $2.05 \pm 2.31 \mathrm{ml}$ and increased to $2.18 \pm 2.64 \mathrm{ml}$ but there was no statistically significant difference $(p=0.915)$.

When the nodules were grouped according to cytological characteristics, we first compared the initial nodule volume size and no difference was observed among the three groups ( $p=0.233$ ).

The changes of nodule volume between initial and last nodule volumes were evaluated and only the colloid nodule group of group 1 had a statistically significant reduction $(p=0.040)$ while the others showed no statistically significant changes (Table II).

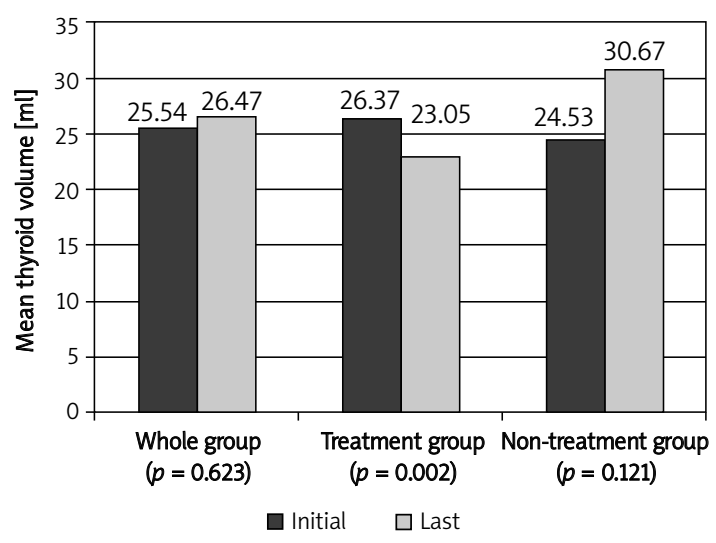

Figure 1. Changes of thyroid volumes in millilitres during the study period 
Table II. Changes in nodule volumes in treatment and non-treatment groups

\begin{tabular}{|c|c|c|c|}
\hline Cytological feature & Initial nodule volume & Last nodule volume & Value of $p$ \\
\hline \multirow[t]{2}{*}{ Treatment group (group $1 ; n=74$ ) } & Mean: $2.57 \pm 2.97$ & Mean: $2.22 \pm 2.75$ & \multirow[t]{2}{*}{0.009} \\
\hline & Median: 1.42 & Median: 1.01 & \\
\hline \multirow[t]{2}{*}{ Adenomatous nodules $(n=33)$} & Mean: $2.13 \pm 2.50$ & Mean: $2.10 \pm 2.81$ & \multirow[t]{2}{*}{0.140} \\
\hline & Median: 1.06 & Median: 0.82 & \\
\hline \multirow[t]{2}{*}{ Colloid nodules $(n=18)$} & Mean: $3.78 \pm 4.55$ & Mean: $2.23 \pm 2.20$ & \multirow[t]{2}{*}{0.040} \\
\hline & Median: 1.56 & Median: 1.22 & \\
\hline \multirow[t]{2}{*}{ Cystic nodules $(n=23)$} & Mean: $2.57 \pm 2.42$ & Mean: $2.42 \pm 3.04$ & \multirow[t]{2}{*}{0.150} \\
\hline & Median: 1.60 & Median: 1.40 & \\
\hline \multirow[t]{2}{*}{ Non-treatment group (group $2 ; n=54$ ) } & Mean: $2.05 \pm 2.19$ & Mean: $2.18 \pm 2.64$ & \multirow[t]{2}{*}{0.915} \\
\hline & Median: 0.86 & Median: 0.97 & \\
\hline \multirow[t]{2}{*}{ Adenomatous nodules $(n=20)$} & Mean: $1.85 \pm 2.21$ & Mean: $2.32 \pm 3.15$ & \multirow[t]{2}{*}{0.443} \\
\hline & Median: 0.86 & Median: 0.97 & \\
\hline \multirow[t]{2}{*}{ Colloid nodules $(n=15)$} & Mean: $2.20 \pm 2.18$ & Mean: $1.73 \pm 2.03$ & \multirow[t]{2}{*}{0.509} \\
\hline & Median: 1.47 & Median: 0.62 & \\
\hline \multirow[t]{2}{*}{ Cystic nodules $(n=19)$} & Mean: $2.24 \pm 2.30$ & Mean: $2.26 \pm 2.35$ & \multirow[t]{2}{*}{0.624} \\
\hline & Median: 0.77 & Median: 1.14 & \\
\hline
\end{tabular}

By omitting the colloid nodules, remaining nodules were re-evaluated. When all subjects were taken into account, the mean nodule volume changed from $2.18 \pm 2.35 \mathrm{ml}$ to $2.25 \pm 2.82 \mathrm{ml}(p=0.101)$. In group 1, mean initial nodule volume was $2.29 \pm 2.45 \mathrm{ml}$ and decreased to $2.21 \pm 2.56 \mathrm{ml}$; the difference was not statistically significant $(p=0.067)$. In group 2 , mean nodule volume was $2.01 \pm 2.22 \mathrm{ml}$ and increased to $2.29 \pm 2.79 \mathrm{ml}$ but there was no statistically significant change $(p=0.701)$.

"Nodule shrinkage," accepted as a decrease in nodule size $\geq 15 \%$, was observed in $64.1 \%$ of nodules of group 1 , while stability (changes in nodule size $<15 \%$ ) and nodule increment (accepted as an increase in nodule size $\geq 15 \%$ ) were found in $15.6 \%$

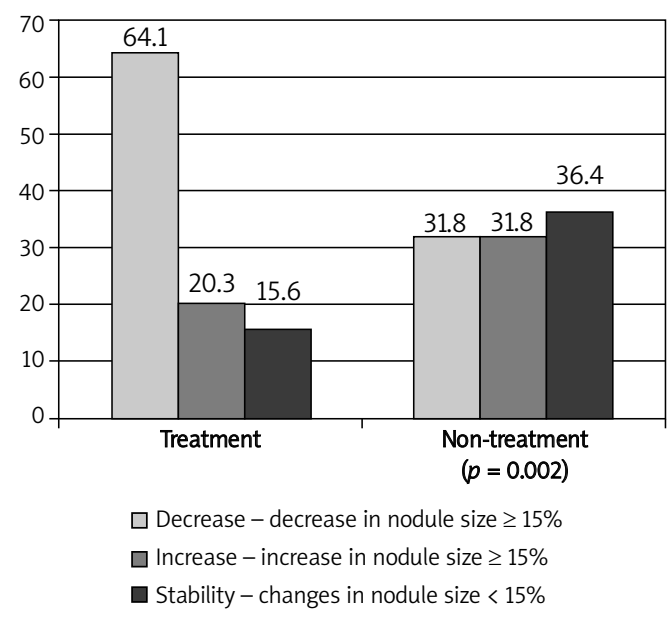

Figure 2. The rates of nodule size alterations for treatment and non-treatment groups and $20.3 \%$ of the nodules of this group respectively. However, coequal rates were observed in group 2; decrease in $31.8 \%$, stability in $36.4 \%$, and increase in $31.8 \%$. The proportional change of nodule volume size between the two groups was found to be statistically significant ( $p=0.002$ ) (Figure 2 ).

In group 1, "nodule shrinkage" was observed in $51.5 \%$ of adenomatous nodules, $75.0 \%$ of colloid nodules and $79 \%$ of cystic nodules, while stability was found in $21.2 \%$ of adenomatous nodules, $8.3 \%$ of colloid nodules and $10.5 \%$ of cystic nodules. Additionally, an increase was observed in $27.3 \%$ of adenomatous nodules, $16.7 \%$ of colloid nodules and $10.5 \%$ of cystic nodules.

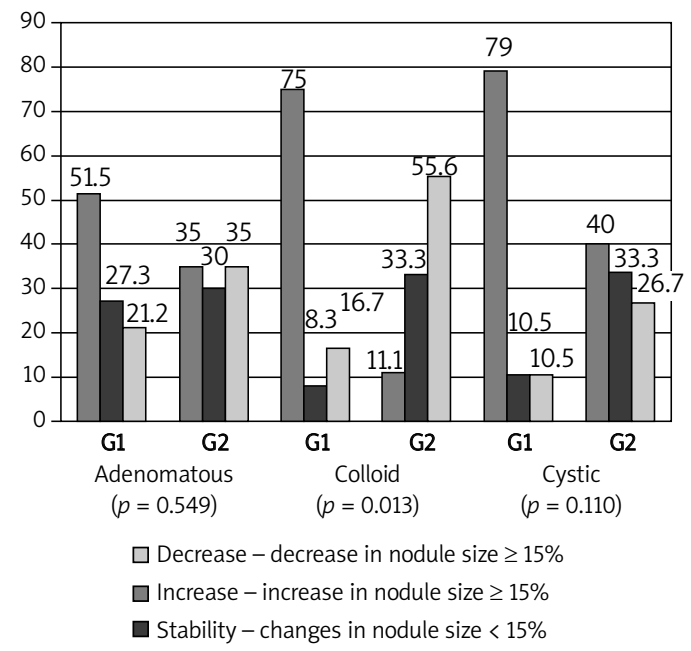

Figure 3. The rates of nodule size alterations according to cytological features

G1 - treatment group, G2 - non-treatment group 
"Shrinkage", stability and increase in nodule sizes were also evaluated in group 2. In adenomatous nodules the rates were similar (35\%,35\% and $30 \%$ respectively). Stability was dominant in colloid nodules (55.6\%) while decrease $(11.1 \%)$ and increase (33.3\%) in nodule size were also found in a part of this group. There was no large difference between the rates of "shrinkage", stability and increase in cystic nodules (40\%, 26.7\% and 33.3\% respectively). When we statistically evaluated the proportional change of nodule volume size among cytological features and treatment groups, only colloid nodules had a statistically significant change ( $p=0.013)$ (Figure 3).

If we evaluate the same data with "clinically significant shrinkage", defined as $>20 \%$ increase in at least two dimensions of the nodule or $50 \%$ increase in nodule volume, neither group had a clinically significant decrease in volume, including colloid nodules with or without treatment [32].

\section{Discussion}

In the medical literature, discussions about treatment of a benign nodule of an endocrine gland are restricted to the thyroid while adenomas of pituitary, adrenal, prostate, gonads or breast are only followed [33]. Although in the last decades there was an attitude to treat nodular goiter with LT4 to suppress TSH [10], this attitude was abandoned because of controversial results on the risk-benefit ratio.

High resolution ultrasonography has become the first-line method in the evaluation of thyroid morphology due to its high sensitivity and ease of use [34]. In our study, changes of the nodule volume from the baseline were sonographically evaluated and LT4 therapy was found to significantly reduce the volume of benign colloid thyroid nodules and thyroid, although this change was not clinically relevant, similar to what was reported in some previous studies [1, 12, 34-37]. In these studies, some thyroidologists prefer to lower TSH level to $0.3 \mathrm{mIU} /$ $\mathrm{ml}$ or below, in the course of LT4 therapy, while others aim to keep it between $0.3 \mathrm{mIU} / \mathrm{ml}$ and $1.0 \mathrm{mIU} /$ $\mathrm{ml}$ [37]. We attended to the second group and showed that low-normal level TSH suppression could be effective for decreasing thyroid nodule volume instead of an LT4-induced subclinical thyrotoxic state.

The influence of cytological features on shrinkage of nodules has been questioned previously and La Rosa et al. reported in particular that colloid nodules and also adenomatous nodules had a tendency to a good response while hyperplastic nodules were resistant to LT4 therapy [24]. However, Vermiglio et al. did not confirm this result and suggested that the frequency of shrinking nodules was not different between colloid, adenomatous and hyperplastic nodules [35]. There are not enough studies in the medical literature to investigate the effect of nodule cytology on LT4 therapy response. In our study, only colloid nodules of the treated group (group 1) had a statistically significant reduction while non-treated colloid nodules did not reveal statistically significant shrinkage, and none of them were at clinically significant levels. However, no significant shrinkage was found in either adenomatous or cystic nodules in this study, in either treated or non-treated patients. We did not include hyperplastic nodules in our study because of the difficulty in differentiating them from follicular neoplasm [29]. The reason for the controversial results may be attributed to the study design of the previous studies. Cystic nodules are known to be resistant to LT4 therapy $[36,38]$, but we think this subject is also controversial. It is believed that patients with exclusively or predominantly solid nodules may be more responsive to this therapy than those with a major cystic component, because thyroid cysts have been shown to recur after aspiration despite treatment with LT4 suppression, especially as regards big cystic nodules [9, 39]. According to a previous study [40], only $4 \%$ of cystic thyroid lesions were pure cystic nodules, $82 \%$ were combined with degenerating benign adenomas or colloid nodules, and 14\% were malignant. In another wide study, there were only one simple thyroid cyst and three hemorrhagic cysts in 550 examined patients [41]. In fact, the nodules initially considered to be cystic were usually mixed lesions: solidcystic [42].

Erdogan et al. reported a nodule size change criterion as change in nodule volume of at least $15 \%$, and found that $33.1 \%$ of thyroid nodules decreased while $32 \%$ of them increased in size, in non-treated nodules [43]. If we relate these findings to the current study, non-treated adenomatous and cystic nodules have similar results; one third of them decreased, one third of them increased, and one third of them remained stable. However, only $11 \%$ of non-treated colloid nodules decreased spontaneously. When we compared treated and non-treated nodules, there was a more striking difference in colloid nodules than the others; $75 \%$ of treated colloid nodules decreased and this may reflect the beneficial effect of LT4 treatment on colloid nodules. In fact, $79 \%$ of treated cystic nodules decreased, but $40 \%$ of non-treated nodules also decreased spontaneously in our study. Sturniolo et al. documented a $79.9 \%$ reduction rate in cystic nodules with treatment after FNAB [44] and Sarda et al. reported a $44.7 \%$ reduction rate without treatment [45]. Our study confirmed that the nodules with evident cystic component have a tendency to shrinkage either with treatment or without treatment. These results may be an effect of FNAB in 
cystic nodules. Previous reports about FNAB of thyroid nodules showed significant individual changes in volume after the procedure and that may support our suggestion [46, 478]. Moreover, Alexander et al. suggested that most cystic nodules are less likely to grow compared with nodules with a greater solid component [48]. Meanwhile, a clinically significant decrease was not achieved with these TSH levels in any of the groups in our study. Therefore, we cannot conclude that LT4 therapy has a clinically significant effect on any type of nodule with these results, but still there may be a statistically significant difference for colloid nodules.

Our study has some limitations. We did not include hyperplastic nodules and therefore we cannot comment on this type of nodule. Another point is that there are no absolute criteria for thyroid volume change [49], so we evaluated only statistical significance for total thyroid volume. Also, it is probable that nodular disease may be of clonal or polyclonal origin independent of TSH levels or might express some markers important in the growth process [50,51]. Therefore the genetic analysis of nodular content or molecular markers might give better information about its response to TSH suppression, which was not performed in our study. We also do not know the iodine status of the patients, but since previous studies in this region showed that iodine supplementation is successful in the study region [28], the effect of iodine levels on study results can be accepted as minimal.

On the basis of these results, obtained from a large sample of Anatolian patients, it is possible that LT4 therapy leads to significant reductions on both thyroid volume and nodule size in colloid nodules, but not in other kinds of benign nodules. Considering the possible side effects of LT4 suppressive therapy, especially occurrence of cardiac dysfunction [52], it seems to be important to know the cytological features of benign thyroid nodules that are responsible for nodule shrinkage, for more appropriate management.

\section{References}

1. Gullu S, Gurses MA, Baskal N, et al. Suppressive therapy with levothyroxine for euthyroid diffuse and nodular goiter. Endocrinol J 1999; 46: 221-6.

2. Roti E, Minelli R, Gardini E, Braverman LE. The use and misure of thyroid hormone. Endocrinol Rev 1993; 14 : 401-23.

3. Hermus AR, Huysmans DA. Treatment of benign nodular thyroid disease. N Eng J Med 1998; 338: 1438-47.

4. Samuels $\mathrm{MH}$. Evaluation and treatment of sporadic nontoxic nodular goiter - some answers and more questions. J Clin Endocrinol Metab 2001; 86: 994-7.

5. Gharib H, Mazzaferri EL. Thyroxine suppressive therapy in patients with nodular thyroid diasese. Ann Int Med 1998; 128: 386-94.
6. Shaha AR. Controversies in the management of thyroid nodule. Laryngoscope 2000; 110: 183-93.

7. Castro MR, Caraballo PJ, Morris JC. Effectiveness of thyroid hormone suppressive therapy in benign solitary thyroid nodules: a meta-analysis. J Clin Endocrinol Metab 2002; 87: 4154-9.

8. Castro MR, Gharib $\mathrm{H}$. Continuing controversies in the management of thyroid nodules. Ann Int Med 2005; 142: 926-31.

9. Celani MF, Mariani M, Mariani G. On the usefulness of levothyroxine suppressive therapy in the medical management of benign, solitary, solid or predominantly solid thyroid nodules. Acta Endocrinologica 1990; 123: 603-8.

10. La Rosa GL, Lupo L, Giuffrida D, Gullo D, Vigneti R, Belfiore $A$. Levothyroxine and potassium iodide are both effective in treating benign solitary solid cold nodules of the thyroid. Ann Int Med 1995; 122: 1-8.

11. Csako G, Byrd D, Wesley RA, et al. Assessing the effects of thyroid suppression on benign solitary thyroid nodules. A model for using quantitative research synthesis. Medicine (Baltimore) 2000; 79: 9-26.

12. Koc M, Ersoz HO, Akpinar I, Gogas-Yavuz D, Deyneli O, Akalin S. Effect of low and high dose levothyroxine on thyroid nodule volume: a cross-over placebo controlled trial. Clin Endocrinol 2002; 57: 621-8.

13. Wemeau JL, Caron P, Schwartz C, et al. Effects of thyroid stimulating hormone supression with levothyroxine in reducing the volume of solitary thyroid nodules and improving extranodular nonpalpable changes: a randomized, double-blind, placebo-controlled trial by the French Thyroid Research Group. J Clin Endocrinol Metab 2002; 87: 4928-34.

14. Zelmanovitz F, Genro S, Gross JL. Suppressive therapy with levothyroxine for solitary thyroid nodules: a double-blind controlled clinical study and cumulative meta-analyses. J Clin Endocrinol Metab 1998; 83: 3881-5.

15. Papini E, Petrucci L, Guglielmi R, et al. Long-term changes in nodular goiter: a 5-year prospective randomized trial of levothyroxine suppressive therapy for benign cold thyroid nodules. J Clin Endocrinol Metab 1998; 83: 780-3.

16. Gharib H, James EM, Charboneau JW, Naessens JM, Offord KP, Gorman CA. Suppressive therapy with levothyroxine for solitary thyroid nodules. A double-blind controlled clinical study. N Eng J Med 1987; 317: 70-5.

17. Reverter JL, Lucas A, Salinas I, Audi L, Foz M, Sanmarti A. Suppressive therapy with levothyroxine for solitary thyroid nodules. Clin Endocrinol 1992; 36: 25-8.

18. Larijani B, Pajouhi M, Bastanhagh MH, Sadjadi A, Sedighi N, Eshraghian MR. Evaluation of suppressive therapy for cold thyroid nodules with levothyroxine: double-blind placebocontrolled clinical trial. Endocrin Pract 1999; 5: 251-6.

19. Gharib H, Papini E, Paschke R, et al. AACE/AME/ETA Task Force on Thyroid Nodule. Endocr Pract 2010; 16: 1-43.

20. Mitra S, Jha M, Gandhi K. Does thyroxine suppression therapy help to rationalize surgery in benign euthyroid nodules? Indian J Nucl Med 2010; 25: 57-61.

21. Corrias A, Mussa A, Wasniewska M, et al. Levothyroxine treatment in pediatric benign thyroid nodules. Horm Res Paediatr 2011; 75: 246-51.

22. Blum M, Hussain MA. Evidence and thoughts about thyroid nodules that grow after they have been identified as benign by aspiration cytology. Thyroid 2003; 13: 637-41.

23. Cesur M, Corapcioglu D, Bulut S, et al. Comparison of palpation guided fine needle aspiration biopsy with ultrasound guided fine needle aspiration biopsy in the evaluation of thyroid nodules. Thyroid 2006; 16: 555-61. 
24. La Rosa GL, Ippolito AM, Lupo L, et al. Cold thyroid nodule reduction with L-thyroxine can be predicted by initial nodule volume and cytological characteristics. J Clin Endocrinol Metab 1996; 81: 4385-7.

25. Cesareo R, lozzino M, Isgrò MA, Annunziata F, Di Stasio E. Short term effects of levothyroxine treatment in thyroid multinodular disease. Endocr J 2010; 57: 803-9.

26. Erdogan MF, Demir O, Emral R, Kamel AN, Erdogan G. More than a decade of iodine prophylaxis is needed to eradicate goitre among school age children in a moderately iodine-deficient region. Thyroid 2009; 19: 265-8.

27. Ertek S, Cicero AF, Caglar O, Erdogan G. Relationship between serum zinc levels, thyroid hormones and thyroid volume following successful iodine supplementation. Hormones (Athens) 2010; 9: 263-8.

28. Erdoğan MF, Ağbaht K, Altunsu T, et al. Current iodine status in Turkey. J Endocrinol Invest 2009; 32: 617-22.

29. Oertel YC, Oertel JE. Thyroid cytology and histology. Baillieres Best Pract Res Clin Endocrinol Metab 2000; 14: 541-57.

30. Suen KC. Fine needle aspiration biopsy of the thyroid. Canadian Med Assoc J 2002; 167: 491-5.

31. Brunn J, Block U, Ruf G, Bos I, Kunze WP, Scriba PC. Volumetric analysis of thyroid lobes by real-time ultrasound. Deutsch Medizin Wochenschrift 1981; 106: 1338-40.

32. Cooper DS, Doherty GM, Haugen BR, et al.; American Thyroid Association Guidelines Taskforce. Management guidelines for patients with thyroid nodules and differentiated thyroid cancer. Thyroid 2006; 16: 109-42.

33. Ridgway EC. Medical treatment of benign thyroid nodules: have we defined a benefit? Ann Int Med 1998; 128: 403-5.

34. Erdogan MF, Anil C, Cesur M, Baskal N, Erdogan G. Color flow Doppler sonography for the etiologic diagnosis of hyperthyroidism. Thyroid 2007; 17: 223-8.

35. Vermiglio F, Lo Presti VP, Violi MA, et al. Changes in both size and cytological features of thyroid nodule after levothyroxine treatment. Clin Endocrinol 2003; 59: 347-53.

36. Kim DW, Rho MH, Kim HJ, Kwon JS, Sung YS, Lee SW. Percutaneous ethanol injection for benign cystic thyroid nodules: is aspiration of ethanol-mixed fluid advantageous? Am J Neurorad 2005; 26: 2122-7.

37. Diehl LA, Garcia V, Bonnema SJ, Hegedus L, Albino CC, Graf H; Latin American Throid Society. Management of the nontoxic multinodular goiter in Latin America: comparison with North America and Europe, an electronic survey. J Clin Endocrinol Metab 2005; 90: 117-23.

38. McCowen KD, Reed JW, Fariss BL. The role of thyroid therapy in patients with thyroid cysts. Am J Med 1980; 68: 853-5.

39. McHenry CR, Slusarczyk SJ, Khiyami A. Recommendations for management of cystic thyroid disease. Surgery 1999; 126: $1167-71$

40. de los Santos ET, Keyhani-Rofagha S, Cunningham JJ, Mazzaferri EL. Cystic thyroid nodules. The dilemma of malignant lesions. Arch Intern Med 1990; 150: 1422-7.

41. Simeone JF, Daniels GH, Mueller PR, et al. High-resolution real-time sonography of the thyroid. Radiology 1982; 145: 431-5.

42. Braga M, Cavalcanti TC, Collaco LM, Graf H. Efficacy of ultrasound-guided fine-needle aspiration biopsy in the diagnosis of complex thyroid nodules. J Clin Endocrinol Metab 2001; 86: 4089-91.

43. Erdogan MF, Gursoy A, Erdogan G. Natural course of benign thyroid nodules in a moderately iodine-deficient area. Clin Endocrinol 2006; 65: 767-71.

44. Sturniolo G, Carditello A, Sobbrio GA, Bartolotta M, Lentini B, Gagliano E. Cytologic aspiration biopsy in the diagnosis and therapy of solitary cystic nodular thyropathies. Minerva Medica 1986; 77: 801-3.

45. Sarda AK, Bal S, Dutta Gupta S, Kapur MM. Diagnosis and treatment of cystic disease of the thyroid by aspiration. Surgery 1988; 103: 593-6.

46. Gordon DL, Flisak M, Fisher SG. Changes in thyroid nodule volume caused by fine-needle aspiration: a factor complicating the interpretation of the effect of thyrotropin suppression on nodule size. J Clin Endocronil Metab 1999; 84: 4566-9.

47. Guney E, Ozgen AG, Kabalak T. Is the effect of fine-needle aspiration biopsy on the thyroid nodule volume important to evaluate the effectiveness of suppression therapy? J Endocrinol Invest 2003; 26: 651-4.

48. Alexander EK, Hurwitz S, Heering JP, et al. Natural history of benign solid and cystic thyroid nodules. Ann Int Med 2003; 138: 315-8.

49. Ertek S, Ersoy Rü, Anil C, et al. Hypothyroidism, new nodule formation and increase in nodule size in patients who have undergone hemithyroidectomy. Arch Med Sci 2012; 8: 263-9.

50. Harrer P, Broecker M, Zint A, Schatz H, Zumtobel V, Derwahl M. Thyroid nodules in recurrent multinodular goiters are predominantly polyclonal. J Endocrinol Invest 1998; 21: 380-5.

51. Krawczyk-Rusiecka K, Lewiński A. Cyclooxygenase-2 expression and its association with thyroid lesions. Arch Med Sci 2010; 6: 653-7.

52. Gullu S, Altuntas F, Dincer I, Erol C, Kamel N. Effects of TSH-suppressive therapy on cardiac morphology and function: beneficial effects of the addition of betablockade on diastolic dysfunction. Eur J Endocrinol 2004; 150: 655-61. 